\title{
DE LA \\ CANDELARIA A \\ LAS LUMBRADAS: \\ EL MESTIZAJE DE \\ UNA TRADICIÓN \\ Herón Pérez*
}

\section{Problemas de la Candelaria con el calendario}

He de febrero de cada año, en una fiesta religiosa que sigue llamándose de la Candelaria, en ciertos barrios de Zamora, como en la Cañada de los Once Pueblos, en Michoacán, aún sobrevive la costumbre de reunirse en tertulia, al atardecer, familiares y amigos, en torno a una lumbrada frente a la puerta de su casa, entre tamales, buñuelos, atole, ponche y demás antojitos navideños, con el pretexto de una serie de rituales, en que se empalma lo religioso con las relaciones de parentesco, y que se han ido configurando en torno al "levantamiento del niño".

Lo que ha dado el nombre a la tradición que nos ocupa es la procesión que en esta fecha se hacía portando candelas benditas. Según el Martirologio Romano la de la Candelaria es la fiesta de la "Purificación de la Virgen María, llamada por los griegos hypapante del Señor". La actual festividad de la Candelaria en la liturgia romana es el resultado del empalme de dos fiestas en una: purificación de María y presentación de

*El Colegio de Michoacán. 


\section{Herón Pérez}

Jesús en el templo. La ambivalencia simbólica de una vela encendida hizo el resto: la luz -símbolo cristológico- y el fuego símbolo de la purificación de María.

Para el hombre occidental común y corriente, las fiestas relacionadas con la Navidad tienen un valor conmemorativo; es decir responden estrictamente a un calendario de algo sucedido hace exactamente 1991 años. Según el mito cristiano, el 25 de diciembre del año uno -o del año cero- de nuestra era, la era cristiana, en Belén de Judá, en un pesebre, María de Nazareth, una virgen desposada con un carpintero también nazarethano llamado José, habría dado a luz a su hijo primogénito Jesús -en realidad hijo de Dios y salvador del mundo-, concebido por obra del Espíritu Santo. Es lo que dice el Martiologio Romano ${ }^{1}$ el 25 de diciembre en su estereotipado y solemne lenguaje. Cuarenta días después, el 2 de febrero, María se habría presentado en el templo con dos palomas para realizar el rito de purificación prescrito en el Levítico a las parturientas. Todo esto habría sido fijado en un calendario por los cristianos primitivos y pasando siglos y milenios habría llegado hasta el 2 de febrero pasado.

\section{El asunto de las fechas}

Pese a la solemnidad del texto del Martirologio, no sabemos la fecha exacta del nacimiento de Jesús de Nazareth. El tercer evangelio trae dos datos: que Jesús de Nazareth nació "en tiempos de Herodes" y que el emperador Augusto mandó "hacer un censo del mundo entero", el primero que se hizo siendo Quirino gobernador de Siria. El primer evangelista, ${ }^{2}$ en cambio, dice que "Jesús nació en Belén de Judea en tiempos del Rey Herodes", que vinieron unos magos de oriente a adorarlo, que Herodes tramaba matar al niño pero que, finalmente, es burlado por los magos con ayuda de un ángel, y que para vengarse mandó matar a todos los niños betlemitas menores de dos años, tiempo en que,

\footnotetext{
${ }^{1}$ Cfr. Martyroloquim Rumanum, Mechelen, H. Dessain, 1903, p. 241.

${ }^{2}$ Mt 2, 1ss.
} 
DE LA CANDELARIA A LAS LUMBRADAS

dijeron los magos, habían visto por primera vez la estrella que los había guiado hasta allí.

Los textos anteriores forman parte de una literatura muy frecuente en los dos primeros siglos de la era cristiana elaborada sobre la base de que, como no se tenían noticias ciertas acerca del nacimiento de Jesús de Nazareth, las comunidades cristianas crearon tradiciones literarias según la idea teológica que se habían formado al respecto. No es éste el momento ni el lugar para mostrar las concepciones tan diferentes entre sí que subyacen a los relatos de la infancia en ambos evangelios. ${ }^{3}$

Quirino llegó a Judea como legado imperial y realizó en el 6 o 7 d.C. un censo de los habitantes y de sus propiedades con fines fiscales. Ya Schürer, ${ }^{4}$ discutió con abundancia de datos y fuentes lo relacionado con este censo de Quirino. Su principal conclusión es que el censo de Quirino no pudo tener lugar en tiempo de Herodes, por no haber sido gobernador de Siria durante la vida de Herodes. ${ }^{5}$

Por otro lado, ya sabemos con certeza que Herodes el Grande murió el año 4 antes de Cristo. ${ }^{6}$ Schürer se encargó de probarlo sin lugar a dudas. Por tanto, y aunque no sabemos con certeza ni el año, ni, mucho menos, el día del nacimiento de Jesús, de acuerdo con los evangelios y según lo dicho sobre la muerte de Herodes, Cristo nació hacia el año 6/7 antes de Cristo. Los textos evangélicos anteriores, como quiera, siguen

${ }^{3}$ Entre el enorme cúmulo de bibliografía que hay sobre el asunto, me permito citar sólo a Raymond E. Brown, El Nacimiento del Mesias, Madrid, Ed. Cristiandad, 1982. Allí encontrará el lector interesado las más importantes referencias bibliográficas sobre el asunto. Véase, especialmente, las páginas $34 \mathrm{~s}, 49 \mathrm{~s}, 90 \mathrm{~s}$, 118s, 163, 200s, 234, 260s, 294, 340s, 381, 410, 453s, 491, 519 y 594. En esta última página, en efecto, Brown ofrece una selecta bibliografía sobre la cuarta égloga de Virgilio que habla, como se sabe, de una virgen y de un nin̄o de origen divino ante quien la tierra entera, temblorosa, se inclinará; y quien dará origen a una edad dorada de paz, cuando desaparezcan los "últimos vestigios de maldad".

${ }^{4}$ Emil Schürer, Historia del pueblo judio en tiempos de Jesús, Vol. I, Madrid, Ed. Cristiandad, 1985, p. 517. Este libro, ahora puesto al día, es conocido, simplmente, como "el Schürer".

${ }^{5}$ E. Schürer, op. cit., p. 515-550.

${ }^{6}$ Schürer, op. cit., p. $424 \mathrm{~s}$. 
Herón Pérez

estando a la base del calendario cristiano en fiestas como la Navidad y la Candelaria.

\section{La fiesta del Sol invicto}

Tampoco se sabe con certeza cuándo se empezó a celebrar la fiesta de Navidad el 25 de diciembre. ${ }^{7}$ Los datos arrojados por la arqueología sólo permiten conjeturas. Por lo pronto, se sabe que en los primeros años, probablemente a principios de siglo II, la fiesta de navidad se celebraba junto con otras dos fiestas teofánicas, los reyes magos y el bautismo de Jesús, unos días después del solsticio de invierno, dentro de los primeros diez días de enero. Del año 336 tenemos el testimonio más antiguo -el calendario filocaliano- de que la celebración de la Navidad tenía lugar, en forma conjunta con las dos fiestas teofánicas señaladas, por esas fechas. Después, en fecha que desconocemos, la Iglesia Romana separó la Navidad de las otras dos fiestas; los armenios monofisitas aún celebran la Navidad el 6 de enero.

El traslado de la fiesta al 25 de diciembre parece haber tenido como objetivo contrarrestar el culto al sol invicto que empezó a tener mucha popularidad en Roma desde Caracalla, quien a principio del siglo III (211-217) había fomentado el culto al dios solar sirio Sol invictus. ${ }^{8}$ Tras la muerte violenta de Heliogábalo ocurrida en 222 , quedó proscrito e! culto alsol entre los romanos; hasta que Aureliano (270-275) lo introdujo con éxito, nuevamente por razones políticas: para asegurar la unidad del Imperio. Al decir de Eliade, "fueron cuidadosamente eliminados los elementos sirios y el servicio se confió a los senadores romanos. Se fijć

\footnotetext{
${ }^{7}$ Sobre esta cuestión, puede consultarse, entre el caudal bibliografico que hay sobre el tema, L. de Echeverría, B. Llorca, S.J., L. Sala Balust y C. Sánchez Aliseda, El año cristiano, 4 tomos, Madrid, BAC, 1960. Véase especialmente el tomo IV. Véase, igualmente, Manuel Garrido O.S.B., Curso de liturgia romana, madrid, BAC, 1961.

${ }^{8}$ Para todo esto véase Mircea Eliade, Historia de las creencias y de las ideas religiosas, vol. I, Madrid, Ediciones Cristiandad, 1979, p. 357-401.
} 
el aniversario del Sol invictus el 25 de diciembre, día natalicio de todas las divinidades solares orientales".

La fiesta cristiana de la navidad parece haber sido trasladada hacia el año 330, en tiempos de Constantino (306-337), al 25 de diciembre. Con ello se quería significar a Cristo como el verdadero Sol invictus. Es importante observar que, a partir del año 315 , empiezan a aparecer en las monedas los primeros símbolos cristianos. Probablemente sea por estas fechas cuando tiene lugar el cambio de la fiesta de Navidad al 25 de diciembre. El mensaje recabado de la célebre visión de Constantino fue en el sentido de la prevalencia de Cristo sobre el Sol: Cristo es el verdadero sol invicto. Sólo faltaba trasladar la fecha del nacimiento de Jesús al 25 de diciembre, día en que se festejaba el nacimiento del Sol invictus.

Esa tradición se encuentra ya firme en el evangelio apócrifo tardío conocido como Liber de infantia salvaturis -probablemente obra de un erudito y elegante compilador carolingio del siglo IX-; presenta a la parturienta que atendió a María en el momento del nacimiento de Jesús diciendo que "el niño lanzaba resplandores, lo mismo que el sol". ${ }^{10}$

\section{El simbolismo del sol}

El simbolismo del sol es múltiple: luz y calor, en primer lugar. El sol es como una gran lumbrada. Éste es, por cierto, el nombre que se le da en la tradición sacerdotal a la creación del sol. ${ }^{11}$ En las lenguas semíticas de una misma raíz ('ur) se derivan tanto los vacablos que significan "luz", como los que significan "fuego" y "candelero". El sol es todo eso: luz, fuego y, ¿por qué no?, una gran candela. Esta tradición es acádica: los

\footnotetext{
${ }^{9}$ Op. cit., p. 358.

${ }^{10}$ Aurelio de Santos Otero, Los evangelios apocrifos, Edición crítica y bilingüe, Madrid, BAC, 1984, p. 266ss.

${ }^{11}$ Gen 14-18.
} 
Herón Pérez

vacablos emparentados, como 'or (la luz), están documentados casi exclusivamente en acádico. ${ }^{12}$

El sol es, en primer lugar, el dador de la luz, porque cada día vence las tinieblas de la noche. Las antiguas culturas se han impresionado siempre por el hecho de que el sol muere cada día y revive cada mañana. Como el hombre que cada noche se sumerge en el sueño-imagen de la muertepara levantarse cada mañana con nuevas fuerzas. Por eso, el sol es la imagen de la estabilidad, la fuente de la vida, los egipcios, al menos durante el período de Akenaton, desarrollaron en el contexto del culto al sol una hermosa literatura. En Heliópolis, por ejemplo, circuló un significativo mito cosmogónico según el cual el sol tuvo al cielo como madre y a la tierra como padre; de acuerdo con el mismo mito fue el dios viento quien en la Creación separó la tierra diel cielo. ${ }^{13}$

Los hebreos conformaron su cultura en contacto con los pueblos vecinos. En su literatura, en efecto, encontramos vestigios sumeroacádicos, hititas, egipcios y, desde lugeo, cananeos, por citar algunas culturas.

Si no el propio dios, para muchos pueblos el sol es una epifanía de la divinidad. Inmortal como Dios, pues resucita infaliblemente por la mañana: la muerte del sol por la tarde hace que la imaginación popular lo vea recorriendo por las noches el reino de los muertos; podrá, por tanto, ser guía de las almas en las regiones infernales y volverlas a llevar al día siguientee, con la mañana, a la luz. En una ulterior abstracción simbólica, Platón ve en el sol la imagen del bien. De hecho, desde muy pronto las culturas utilizaron las categorías luz -tinieblas en sentido moral; y si el sol es epifanía de Dios, entonces Dios es la luz de los hombres. Fuente de luz, de calor y de vida, los rayos del sol representan también las influencias celestes o espirituales recibidas por la tierra. El sol es símbolo del conocimiento intelectivo. Según los antiguos mexica-

12 Cfr. E. Jenni / C. Westermann, Diccionario teológico manual del Antiguo Testamento, Madrid, Ed. Cristiandad, 1978, p. 148. Véase, igualmente, G.J. Botterweck / H. Ringgren, Diccionario teológico del Antiguo Testamento, Madrid, Cristiandad, 1973, p. 161.

${ }^{13}$ En G.J. Butterwack / H. Ringgren, op. cit., p. 162. 
nos vivimos en la era del quinto sol, bajo el signo de Xiuhtecutli, una de las divinidades del fuego. El sol es luz y es fuego, como una vela encendida, como una lumbrada.

\section{La luz}

El simbolismo de la luz alimenta las tradiciones más remotas de las culturas más antiguas. Los conceptos de luzy tienieblas asumieron desde el antiguo Egipto un importante sentido espiritual: la luz es vida, liberación, prosperidad, salvación, felicidad, éxito.

Por los ya sabidos vínculos entre el cristianismo y la comunidad esenia de Qum-Ram y los no menos conocidos entre ciertos círculos gnósticos y el cristianismo, la luz es importante para la simbología cristiana y, por tanto, para la mentalidad occidental. El cuarto evangelio, por ejemplo, llama a Jesús "la luz verdadera, que alumbra a todo hombre" (Juan, 1,9) y lo hace decir, antes de curar a un ciego de nacimiento, "yo soy la luz del mundo, el que me sigue no camina a oscuras" (Juan, 9,5). Jesús es el sol de la verdad, el sol invicto, o, como dice Hesiquio de Batos, "sol que irradia la justicia": ello hace que el simbolismo de la luz enfatice sus vínculos con el fuego. Cristo, como el sol y como la candela, es a la vaz fuego que purifica y luz que alumbra. En el ritual del bautismo cristiano se le entrega al bautizando una vela encendida simbolizando a Cristo. El arraigo de este simbolismo en el ceremonial cristiano puede verse, por ejemplo, en el hermoso texto denominado "pregón pascual" y que es, simplemente, un himno a la luz.

En la literatura de Qumram, ${ }^{14}$ para el libro conocido como Regla de la guerra (IQM) la historia es una guerra permanente entre dos bandos: los hijos de la luz contra los hijos de las tinieblas.

La idea de que el conocimiento es luz y la ignorancia tinieblas se

${ }^{14}$ Entre la numerosa bibliografía existente actualmente sobre Qumram cito a M. Delcor / E. García Martínez, Introducción a la literatura esenia de Qumram, Madrid, Cristiandad, 1987; Luigi Moraldi (editor), I manoscritto di Qumram, Turin, Unione Tipografico-editrice Torinese, 1971. 


\section{Herón Pérez}

encuentra en el núcleo del gnosticismo cuyos vínculos con algunas de las tradiciones cristianas primitivas ya han sido señalados. La gnosis plantea que el conocimiento de Dios está en el conocimiento de sí mismo, pues el ser humano no es otra cosa que una centella de luz divina prisionera en el cuerpo humano; además, según la antropología gnóstica, el hombre está dotado de la psiqué, potencia injertada en el yo que pugna por mantenerlo en tienieblas.

Que esta espiritualidad arraiga en Occidente lo muestra Tomás de Kempis quien, a principios del siglo XV, en su célebre libro-La imitación de Cristo- describe la vida cristiana precisamente como una "imitación de Cristo", cuyo objetivo consiste en "ser de veras iluminados y vernos libres de toda ceguera del corazón".

Para San Juan de la Cruz, uno de los más genuinos representantes de la mística española del siglo XVI, la vida es para el hombre como una noche oscura; empero, por la fe el humano puede "llegar a la divina unión de amor" ${ }^{16}$ que es la luz, por encima de toda ciencia. En el mismo sentido se expresa Santa Teresa en su poesía titulada "Monjas del Carmelo". ${ }^{17}$

Según don Marcelino Menéndez y Pelayo, los mismos terrenos fértiles que vieron crecer y alimentaron la mística del siglo XVI darán origen a una serie de sectas místicas -entre las que hay que mencionar, en primer lugar, el iluminismo y el pietismo-de las que da ampliamente cuenta don Marcelino en su erudita Historia de los heterodoxos españoles. ${ }^{18} \mathrm{Del}$ arraigo que este tipo de simbolismo de la luz mostró en los niveles más profundos de la religiosidad popular cristiana dan fe las numerosas huellas que estas sectas dejaron en los archivos novohispanos de la Inquisición.

El simbolismo de la luz, por lo demás, es prácticamente uno de los

${ }^{15}$ De entre la numerosa bibliografía existente sobre la gnosis, por razones prácticas cito sólo a Elaine Pagels, Los evangelios gnósticos, Barcelona, Ed. Grijalbo, 1982, espeiclamente p. 170 y siguientes; Robert Haardt, "Gnosis", en Sacramentum Mundi, Vol. III, Barcelona, Herder, 1984, p. 291s.

${ }^{16}$ San Juan de la Cruz, "Subida al Monte Carmelo" en Obras completas, undécima edición, Madrid, BAC, 1982, p. 149.

${ }_{17}$ Obras completas, séptima edición, Madrid, BAC, 1982 , p. 514.

${ }^{18}$ 3a. edición, Vol. II, Madrid, BAC, 1978, p. $145 \mathrm{~s}$. 


\section{DE LA CANDELARIA A LAS LUMBRADAS}

universales de la cultura. Tanto para la Qabbalah, el Corán, el Rig-Veda o el mazdeísmo, por no mencionar sino un par de ejemplos, aparece la luz como la forma suprema en la transformación de la realidad, el paradigma de la vida, de la felicidad, del triunfo. La contraposición luz-tinieblas es analogada, en muchas culturas, a la oposición vida-muerte, cielo-tierra. La luz es vida; las tinieblas, muerte. En las imágenes de la China antigua una época sombría va siempre seguida de una época luminosa, pura, regenerada. ${ }^{19}$

En concreto, del simbolismo del sol, la magna luminaria, la liturgia romana retomó, valiéndose de una cotidiana y práctica candela, dos elementos: la luz que ilumina y el fuego que purifica. La luz, como el sol mismo, era desde la Biblia un símbolo cristológico: la luz impregna todos los rincones de la comprensión que el hombre -sobre todo el heredero del judeocristianismo- tiene de su realidad, como caminante por un sendero que se transita al paso del tiempo en el trayecto de la vida humana; luz es acertar la pisada, no salirse del camino, esperar una meta al final; $y$, por eso, la luz es gozo, esperanza, felicidad: es vida.

En la ceremonia del fuego y en la procesión con el cirio encendido en el fuego nuevo recién bendito, la liturgia pascual cristiana ofrece el sentido que originalmente se daba a la procesión con las candelas en la epifanía de la Candelaria; el resucitado es la luz del mundo, la otra fiesta empalmada en la Candelaria es la de la purificación de María, idea asociada por las más antiguar culturas al fuego.

\section{Fuego}

Muchas culturas conocen, en efecto, rituales ígnicos. Como el agua, el fuego es símbolo de transformación y regeneración: de allí el sentido del ritual del fuego nuevo. Para muchas culturas primitivas, entre ellas las mesoamericanas, el fuego es una emanación del sol, es su representante sobre la tierra. Por eso se le relaciona con el rayo y el relámpago, y

${ }^{19}$ Cfr. J. Chevalier / A. Gheerbrant, Diccionario de los símbolos, Barcelona, Herder, 1986, p. 663. 


\section{Herón Pérez}

también con el oro. Frazer recoge muchos rituales en los que se atribuye a las antorchas, las lumbradas, las ascuas y aun a las cenizas, el poder de provocar el crecimiento de las siembras y el bienestar de humanos y de animales.

Las interpretaciones que se suelen dar a los festivales ígnicos son, por lo general, dos: para unos se trata de magia imitativa, cuyo objetivo es asegurar la provisión de luz y calor en el sol: que el sol no se apague; para otros, el fuego tiene una función purificatoria y apotropaica. De hecho, estas dos interpretaciones son complementarias. ${ }^{20}$

El fuego, pues, purifica, regenera y protege. Amén de la ceremonia del fuego nuevo mencionada, la tradición católica festeja la venida del espíritu sobre la naciente iglesia el día de Pentecostés, que desciende en forma de lenguas de fuego que se posan sobre los asustados discípulos del nazareno muerto en la cruz.

Por otra parte, la ambivalencia del fuego proviene de su carácter destructor. El fuego aparece como elemento de castigo en el infierno cristiano. Sin embargo, el fuego es el elemento principal de los ritos de purificación en las culturas agrarias. Los campos son incendiados para que se embellezcan luego con el manto verde de la naturaleza que revive. En el Popol-Vuh, por ejemplo, los héroes gemelos, dioses del maíz, perecen sin defenderse en la pira encendida por sus enemigos, para renacer luego, encarnados en el brote verde del maíz.

Los rituales del fuego nuevo, a veces, como en la quema antes de la siembra, perpetúan con otra, la imagen del grano que muere para renacer. Otras veces tienen un carácter apotropaico. La ceremonia del fuego nuevo en la cultura náhuatl tenía, en efecto, este carácter: era una ceremonia de conjura. Al cumplirse los 52 años del siglo mesoamericano, a la media noche del último día, se tenía que encender el fuego nuevo para conjurar el peligro que con el siglo viejo se acabara también el mundo. Corona Núñe ${ }^{21}$ refiere la transferencia de este ceremonial a Tingambato, vocablo que significa, precisamente, lugar "donde se encien-

${ }^{20}$ Véase Juan Eduardo Cirlot, Diccionario de símbolos, Barcelona, Labor, p. 209 s.

${ }^{21}$ José Corona Núñez, Mitología tarasca, Morelia, Michoacán, SEP, p. 35s. 
de el fuego nuevo". En todo caso, en la ceremonia del fuego nuevo lo importante es su función; proteger el nuevo siglo de los males que lo amenzaban. El fuego para los aztecas era, ante todo, motor de la regeneración periódica.

\section{Las lumbradas zamoranas: donde las tradiciones se juntan}

La lumbrada es el único elemento de los que integran la Candelaria zamorana que no tiene una relación directa con el ciclo navideño cristiano. A la puerta de cada hogar, en los barrios en que esto aún perdura, al atardecer se enciende una gran fogata en torno a la cual se reúnen en tertulia los parientes y amigos a comer tamales, buñuelos y atole para, quizás, después "levantar" al niño. Es cierto que la lumbrada tiene en común con las candelas la luz y el fuego y, desde luego, su referencia al sol. Pero es de índole distinta. La candela es una luz que acompaña, es movible, la lumbrada es estática, no se mueve; se parece más a un acto de ritual.

Como sea, es uno de los elementos típicos de la fiesta del 2 de febrero en el Bajío Zamorano. Hay zamoranos que aún recuerdan las grandes lumbradas que circundaban Zamora desde Los Espinos, San Juan, La Escondida, La Rinconada o La Sauceda en donde habían quienes se disputaran las mejores rajas de ocote para que ardieran toda la noche entre ponches, buñuelos, tamales, atole y plática de la familia reunida en torno al fuego. El deslizamiento del Cristo Sol Invicto a la lumbrada es bien perceptible semánticamente. El sol es luz y es fuego, como las candelas, como las lumbradas. Como en las euroasiáticas, también entre las tradiciones americanas se aprecia el simbolismo de la luz y el fuego y el del sol.

El sol, ya se sabe, es el elemento central de las principales cosmogonías mesoamericanas. Una de ellas imagina una reunión de dioses primordial que crea al sol y le asigna la función de alumbrar el mundo y de poner orden en el caos cósmico. Con el nacimiento del sol empieza la vida cotidiana. $^{22}$

${ }^{22}$ Cfr. Luis Reyes García, Pasión y muerte del Cristo Sol, p. 45. 


\section{Herón Pérez}

Entre los textos de los días de la conquista que han llegado hasta nosotros hay uno que es conmovedor por muchas razones. Se le conoce como El libro de los coloquios. ${ }^{23}$ Se trata, en pocas palabras, de las estratagemas y presiones que ejercieron aquellos frailes sobre los intelectuales nahuas para que se convirtieran al cristianismo. Allí aparece el culto al sol entre las cosas más combatidas y vituperadas por los frailes. ${ }^{24}$

En la cultura mexicana contemporánea no son raras las instituciones, tanto religiosas como profanas, mitad europeas o asiáticas y mitad nativas. Se puede decir que son instituciones mestizas. En el refranero mexicano, por ejemplo, abundan los refranes mestizos: la mayor parte de las veces la estrüctura paremiológica es española y los simbolismos o el sentido son mexicanos. También hay mitos mestizos. Sin duda, la más ilustre de las tradiciones mestizas es, desde luego, la Virgen de Guadalupe. Es que el pueblo moldea las tradiciones, no importa su índole, hasta darles un estilo propio, el estilo tradicional. ${ }^{25}$

Es muy sabido que una de las técnicas usadas por los primeros frailes predicadores fue la de conciliar las tradiciones nativas con los dogmas predicados buscando equivalencias. Así, San Juan Bautista encontró su homólogo americano en Huracán, María en la luna. Tonantzin fue sustituida por la Virgen de Gudalupe. Quetzalcoatl por Santo Tomás,

${ }^{23}$ Don Miguel León Portilla acaba de hacer una hermosa edición con el nombre de Coloquios y doctrina cristiana. Con que los doce frailes de San francisco, eviados por el papa Adriano VI y por el emperador Carlos $V$, convirtieron a los indios de la Nueva España. Edición facsimilar, introducción, paleografía, versión del náhuatl y notas de Miguel León Portilla, México, UNAM, 1986.

${ }_{24}^{24}$ p. 115.

${ }^{25}$ Como ejemplo de este mestizaje literario podríamos mencionar a la literatura hagiográfica que abundo, por ejemplo, en el siglo XVII novohispano; aunque con profundas raíces en la literatura española profana, la trama de esta literatura está tejida en torno a estructuras textuales hagiograficas y tiene como finalidad principal justificar reivindicaciones criollas. Este caudal literario aún aguarda a los estudiosos que lo saquen del olvido y le quiten las ignominias en que lo tienen sumido tan to los imperantes tabúes laicistas como las asechanzas siempre a flor de piel del clericalismo político mexicano. 
etc. Luis Reyes muestra las numerosas correspondencias entre Huitzilopochtli, hijo del Sol, dios de la luz, y Cristo. ${ }^{26}$

Fiesta de año nuevo o fiesta del fuego nuevo, la lumbrada con sus reminiscencias de los tiempos ya remotos en que se gestaban las tradiciones, parece rescoldo de fogones ancestrales. Se desconoce con certeza el origen del pueblo puréhpecha. Aunque la mayor parte de las explicaciones los quieren emparentar con los aztecas. A ello se opone "la lengua tarasca que por ningún lado está afiliada con la náhuatl y que generalmente se clasifica como familia aparte, entre las lenguas mexicanas". 27 De cualquier modo, al tiempo de la conquista "habían absorbido mucho del patrón cultural de Mesoamérica". 28 Por lo demás, los puréhpecha no eran el único grupo indígena en Michoacán al tiempo de la conquista española: estaban los matlazincas o pírindas, grupo otomiano venido del valle de Toluca. Y un grupo de nahuahablantes conocidos como tecos o teocuitlatecos que, llegados a la región antes que los puréhpecha, se fundieron con los habitantes anteriores.

No sería pues descabellado ante el desconocimiento que tenemos de los calendarios michoacanos, apoyarnos en paralelos nahuas y en las actuales tradiciones puréhpecha. La relación de Michoacán, incompleta, sólo trae una mención -y ésta despectiva- al calendario.

Sin embargo, también entre los puréhpecha el Sol era la divinidad principal bajo el nombre de Curicaueri. De allí que el fuego sea el elemento central de las tradiciones puréhpechas. Curicaueri, en efecto, cuyo nombre significa el Gran Fuego o la Gran Lumbrada, es al mismo tiempo dios del fuego y dios solar. El mandamiento principal puréhpecha era traer leña para los cues y mantener el fuego siempre encendido. La obligación fundamental del Cazonci, monarca absoluto, era, además de conquistar la tierra en nombre de Curicaueri, mantener siempre vivo el fuego en los templos, principalmente en el de Tzintzuntzan.

\section{${ }^{26}$ Luis Reyes, op. cit., p. 50.}

${ }^{27}$ Benedict Warren, La conquista de Michoacán 1521-1530, segunda edición, Morelia, Fimax, 1989, p. 9-10.

28 Ibid.

${ }^{29}$ Cfr. Corona Núñez, op. cit., p. 27-32. 
Herón Pérez

"Las fiestas suceden en un tiempo sagrado", dice Eliade, ${ }^{30}$ parten del deseo de abolir el tiempo profano ya transcurrido y de instaurar un tiempo nuevo: son cortes de tiempo que tienen que ver con la renovación de las reservas alimenticias para asegurar la continuidad de la vida de la comunidad. Los ritos de celebración de año nuevo tienen también, por lo general, un carácter apotropaico y purificatorio. ${ }^{31}$

¿Por qué no pensar, entonces, que como aquellas fogatas rituales que purificaban de presagios el ambiente para la llegada del nuevo siglo en el mundo náhuatl, la lumbrada es a la par que una reminiscencia de las fogatas religiosas ancestrales, una ceremonia de conjura para recibir el año nuevo? De hecho, actualmente las comunidades puréhpecha celebran el año nuevo la noche de cada primero de febrero con la ceremonia del fuego nuevo. ¿Por qué no imaginar las antiguas fiestas de año nuevo entre los puréhpecha como una magna lumbrada? ¿Por qué no pensar en algún ciclo agrícola que daba comienzo a principio de febrero? ¿Por que no, en fin, pensar en la lumbrada como una de esas tradiciones mestizas -mitad euroasiáticas y mitad indígenas-que, aunque bautizada, conserva los restos de la antigua ceremonia de año nuevo?

Entre los indicios que de ello ofrecen las culturas indomexicanas menciono, para este propósito, los siguientes. En pirmer lugar, la tradición del comienzo del año agrícola en Astacinga, Veracruz, recogida con estas palabras por Oswaldo A. Romero Melgarejo. ${ }^{32}$

Antes de realizarse las siembras de maíz, chícharos y otros productos, se llevan los granos al templo católico donde el sacerdote visitante los bendice en la misa que se celebra en honor de la Virgen de la Candelaria en el mes de febrero.

\footnotetext{
${ }^{30}$ Mircea Eliade, Tratado de historia de las religiones, México, Era, 1972, p. 355.

${ }^{31}$ Mircea Eliade, El mito del eterno retorno, Buenos Aires / Barcelona, Emecé Editores, 1960, Colección Piragua, p. $57 \mathrm{~s}$.

${ }^{32}$ La castellanización como efecto de la migración temporal: el caso de Astacinga, Ver., Xalapa, tesis presentada en la Fac. de Antropología de la Univ. Veracruzana, 1979, p. 138.
} 


\section{DE LA CANDELARIA A LAS LUMBRADAS}

Para esta comunidad indígena, la renovación de las siembras tiene lugar en febrero, en la misa de la Candelaria, donde se bendicen las semillas para el nuevo ciclo agrícola, condición para que tenga lugar dicha renovación. Con ello comienzan los trabajos de siembra del maíz y del frijol, sobre todo.

En segundo lugar, aunque poco se sabe del carácter agrícola de los antiguos puréhpecha, y aunque se les conoce más como guerreros, cazadores y artesanos excelentes, tenían, sin embargo, en Cuerauáperi una diosa de la agricultura. Ella mandaba las nubes, era la Tlaloc tarasca; pero era también una diosa de la agricultura: ella era la fuente de las semillas y de las cosechas.

Pues bien, las actuales comunidades puréhpecha celebran cada 1 de febrero, al filo de la media noche, su comienzo de año: la hora del nacimiento del año es dada por los astrónomos nativos según la colocación de las estrellas. Año con año, se reúnen los petámuti para designar a la comunidad que el año próximo organizará la fiesta de año nuevo el próximo primero de febrero. No falta quien en efecto, relacione la lumbrada con la fiesta de Tzitanzcuar o fiesta de la resurrección del sol entre los puréhpecha.

En tercer lugar, en poblaciones como Tacuro e Ichán, en la Cañada de los Once Pueblos, donde las lumbradas aún sobreviven con vigorosa intensidad, son apagadas con escobas por niños, con la convicción de que al barrer la lumbre para apagarla, están acabando con el diablo: barrer la lumbrada es matar al diablo para así poder esperar al niño Dios. De nuevo aparece la función apotropaica de la lumbrada y de nuevo está conectada con el nacimiento del año nuevo, que aquí fue sustituido por el niño Dios en un evidente acto de "bautismo". En otras poblaciones michoacanas aún persisten los vínculos de la Candelaria con el comienzo del año agrícola: por ejemplo, los chayotes se siembran después de la Candelaria.

En fin, de epifánica que era, la vieja fiesta de la Candelaria atravesó el tiempo como fiesta de purificación y fin de la cuarentena puerperal de María, la madre de Jesús; la ceremonia de la bendición y procesión con candelas encendidas, símbolo de la luz del sol invicto que al venir al mundo ilumina a todo ser humano, dio pie a que los misioneros transfor- 


\section{Herón Pérez}

maran la ceremonia del fuego nuevo, con ocasión del año nuevo puréhpecha, fiesta de la resurrrección del sol, en las lumbradas de la Candelaria: anuncio de año nuevo; y, desde luego, reminiscencia de los viejos ciclos agrícolas que por estas fechas daban comienzos en los dominios del dios sol. Para las comunidades puréhpecha, por tanto, el día de la Candelaria es el primer día de un año nuevo. 